\title{
Türkiye'de Petrol Fiyatları ve Reel Döviz Kuru İlişkisinin Asimetrik Fourier Nedensellik Analizi ile İncelenmesi*
}

\section{Relationship Between Oil Prices and Real-Exchange Rate in Turkey: An Investigation Using Asymmetric Fourier Causality Analysis}

\author{
Fatma KIZILKAYA ${ }^{1}$ (D)
}

\section{Öz}

Türkiye gibi petrol ithal eden gelişmekte olan ülkeler petrol fiyatlarındaki artıştan olumsuz etkilenebilmektedir. Petrol fiyatlarının artması petrol ithal eden ülkelerde üretim maliyetlerinin ve dolayısıyla fiyatlar genel düzeyinin yükselmesine neden olabilmektedir. Ayrıca, uluslararası piyasalarda petrol fiyatlarının artış göstermesi petrol ithal eden ülkelerin dış ticaret dengelerini de olumsuz etkileyebilmektedir. Bu çalışmada Türkiye için 19602019 dönemi yıllık veriler kullanılmış ve petrol fiyatları ile reel döviz kuru değişkenleri arasındaki asimetrik nedensellik ilişkileri araştırılmıştır. Bu doğrultuda hem petrol fiyatları ile reel döviz kuru serileri arasındaki hem de bu serilerin pozitif ve negatif şokları arasındaki nedensellik ilişkileri Fourier Toda-Yamamoto yöntemi kullanılarak incelenmiştir. Elde edilen sonuçlar petrol fiyatları ile reel döviz kuru değişkenleri arasında simetrik nedensellik ilişkisinin olmadığını, buna rağmen pozitif petrol fiyatı şoklarından pozitif reel döviz kuru şoklarına doğru tek yönlü nedensellik ilişkisinin olduğunu göstermektedir. Yani petrol fiyatlarının artması Türkiye'de reel döviz kurunun artmasına neden olmaktadır. Bu sonuçlara göre, Türkiye'de petrol fiyatları ile döviz kuru ilişkisi incelenirken asimetrik etkilerin göz önünde bulundurulması gerekmektedir.

Anahtar kelimeler: Reel döviz kuru, Petrol fiyatları, Asimetrik fourier nedensellik testi

JEL Sınıflaması: C32, F31, Q43

\begin{abstract}
Oil-importing developing countries such as Turkey may be adversely affected by the increase in oil prices, which can raise production costs and the overall level of consumer prices. Increases in oil prices in international markets may also adversely affect the foreign trade balance of oil-importing countries. In this study, annual data for the period 1960-2019 in Turkey are used to investigate asymmetric causality relationships between oil prices and real exchange rate variables. Causality relationships between oil prices and real exchange-rate series, and between positive and negative shocks of these series, are examined using
\end{abstract}

*Bu çalışma Uluslararası Katılımlı Ekonomi Araştırmaları ve Finansal Piyasalar (IERFM2021) Kongresinde sunulan "Türkiye'de Petrol Fiyatları ve Reel Döviz Kuru İlişkisi: Asimetrik Fourier Nedensellik Analizi" adlı bildirinin gözden geçirilmiş ve düzenlenmiş halidir.

${ }^{1}$ Dr. Öğr. Üyesi, Malatya Turgut Özal Üniversitesi, Sağlık Bilimleri Fakültesi, Malatya, Türkiye

ORCID: F.K. 0000-0002-1028-9341

Sorumlu yazar/Corresponding author: Fatma KIZILKAYA, Malatya Turgut Özal Üniversitesi, Sağlık Bilimleri Fakültesi, Malatya, Türkiye

E-posta/E-mail: fatma.kizilkaya@ozal.edu.tr

Başvuru/Submitted: 05.11.2021

Revizyon Talebi/Revision Requested: 22.11.2021

Son Revizyon/Last Revision Received: 02.12.2021

Kabul/Accepted: 02.12 .2021

Atıf/Citation: Kizilkaya, F. (2021). Türkiye'de petrol fiyatları ve reel döviz kuru ilişkisinin asimetrik fourier nedensellik analizi ile incelenmesi. Istanbul iktisat Dergisi - Istanbul Journal of Economics, 71(2), 549-568. https://doi.org/10.26650/ISTJECON2021-1019608 
the Fourier Toda-Yamamoto method. The results show no symmetric causality relationship between oil prices and real exchange rate variables. However, a one-way causality relationship is revealed from positive oil price shocks to positive real exchange rate shocks, indicating that an increase in oil prices causes an increase in the real exchange rate in Turkey.
According to these results, asymmetric effects should be considered when examining the relationship between oil prices and exchange rates in Turkey.

Keywords: Real exchange rate, Oil prices, Asymmetric fourier Toda-Yamamoto causality test JEL Classification: C32, F31, Q43

\section{EXTENDED ABSTRACT}

Petroleum and petroleum products are vital for the continuous operation of economic operations in countries around the world. Petroleum products are also an important foreign trade commodity that generates considerable income for oil-exporting countries, as well as an imperative production input of significant expenditure for oil-importing countries. These two opposing effects also represent an essential export/import commodity subject to trade between countries. Export revenue from petroleum products in the international market and import expenditure for petroleum products are among the critical variables that determine countries' macroeconomic performance. For this reason, in the face of sudden shocks in global markets (e.g., oil supply-demand and exchange rate shocks), countries may face adverse conditions, such as stagnant economic growth, decreased foreign trade, and inflation, which can have negative effects on national welfare.

The USD dollar, which has the uppermost share in international reserve currency status, has a major influence in the international trade of petroleum products, like many other products. Undoubtedly, fluctuations in the dollar exchange rate have differing effects on oil exporting and importing countries. An overvalued dollar exchange rate may cause more costly imports for oil-importing countries resulting in foreign trade deficits. Therefore, negative exchange rate shocks that occur in global markets may cause a decrease in countries' foreign trade income or an increase in costs, affecting important macroeconomic variables such as inflation, savings, and economic growth in particular. In this sense, the important relationship between oil prices and exchange rates is followed closely by both policymakers and investors. 
The demand for petroleum and petroleum products, which are an essential production input for countries' economic performance, is rising in Turkey, as well as on a global scale. Due to limited reserves, most of Turkey's crude oil needs are met through imports. Consequently, determining the direction of causality between oil prices and exchange rates can provide vital information for policymakers and investors to better understand the dynamics of the relationship. This study investigates symmetric and asymmetric causality relationships between oil prices and real exchange rate variables using annual data for the period 19602019 for Turkey. Both the relationship between crude oil prices and real exchange rate series and the causality relationships between positive and negative shocks of these series are examined using the Fourier Toda-Yamamoto method. The results show no symmetric causality relationship between oil prices and real exchange rate variables; however, a one-way causality relationship is revealed from positive oil price shocks to positive real exchange rate shocks, indicating that the increase in oil prices causes an increase in the real exchange rate in Turkey. According to these results, asymmetric effects should be considered when examining the relationship between oil prices and exchange rates in Turkey. Oil imports are crucial in the sustainability of economic activities in Turkey. In this sense, the increase in oil prices will increase Turkey's import expenditure and thus foreign exchange demand. The increase in the demand for foreign currency puts pressure on the exchange rates in Turkey due to limited alternative income sources. Increases in the exchange rate adversely affect the macroeconomic balances of the country, principally, account deficit and cost inflation. In this sense, long-term policies to reduce dependence on petroleum products should be developed and strongly advocated. It is recommended to implement structural reforms that encourage the diversification of energy consumption, particularly through the development of alternative clean energy sources (such as solar, wind, nuclear, and hydroelectric). 


\section{Giriş}

19. yüzyılın başlarından itibaren küresel ölçekte meydana gelen sanayileşme süreci ve beraberinde gerçekleşen teknolojik ilerlemeler, petrol ve/veya petrol ürünleri kullanımının yoğun bir şekilde artmasına ve bu ürünlerin günümüz üretim süreçleri için vazgeçilmez bir unsur (girdi) halini almasına imkân sağlamıştır. Ancak bu durum, ülkelerin dünya üzerinde adil bir dağılıma sahip olmayan hammadde kaynaklarına ulaşma veya kullanma anlamında eşit fırsatlara sahip olduğu anlamına gelmemektedir. Petrol İhraç Eden Ülkeler Örgütü (OPEC) (2013) tarafından yayınlanan veriler, dünyadaki kanıtlanmış petrol rezervlerinin \%81'inin OPEC ülkelerinde bulunduğuna ve söz konusu rezervlerin \%66'sının ise Orta Doğu ülkelerinde yer aldığına işaret etmektedir.

Ekonomik faaliyetlerin sürdürülebilirliği açısından petrol ve petrol ürünleri ülkeler için hayati bir öneme sahiptir. Bu ürünler petrol ihracat eden ülkeler için gelir yaratabilen önemli bir dış ticaret ürünü, petrol ithal eden ülkeler için ise harcamaya neden olan önemli bir üretim girdisi olarak nitelendirilebilir. Söz konusu iki karşıt etki aynı zamanda ülkeler arasında dış ticarete konu olan en önemli ihracat/ithalat kalemini de ifade etmektedir. Günümüzde uluslararası piyasa fiyatlarında petrol ürünlerinden elde edilen ihracat gelirleri veya petrol ürünlerine ödenen ithalat giderleri ülkelerin makroekonomik performansların belirleyen en önemli değişkenler arasında yer almaktadır. Bu nedenle küresel piyasalarda yaşanan ani şoklar (petrol arz-talep, döviz kuru şokları vb.) karşısında ülkeler başta ekonomik büyüme, dış ticaret ve enflasyon gibi olumsuz koşullarla karşılaşabilmekte ve bu durum refah artışları üzerinde olumsuz etkiler meydana getirebilmektedir.

Uluslararası rezerv para birimi statüsünde en önemli paya sahip olan USD, pek çok ürün gibi, petrol ürünlerinin ticaretinde de başlıca rol üstlenmektedir. Kuşkusuz döviz kuru dalgalanmalar petrol ihraç eden ve ithal eden ülkeler üzerinde farklı etkilere sahiptir. Aşırı değerli kur, petrol ithal eden ülkeler için daha maliyetli bir ithalatın oluşmasına ve bu ülkelerin dış ticaret açığı vermelerine neden olabilmektedir. Diğer taraftan döviz kuru yaşanacak değer kayıpları ise petrol ihracat eden ülkelerin ihracat gelirlerinin azalmasına ve beraberinde büyüme 
performanslarının olumsuz etkilenmesine yol açabilmektedir. Dolayısıyla küresel piyasalarda meydana gelebilecek olumsuz kur şokları, ülkelerin dış ticaret gelirlerinin azalması veya maliyetlerinin artmasına, dolayısıyla başta ekonomik büyüme olmak üzere enflasyon ve tasarruflar gibi önemli makroekonomik değişkenlerin etkilenmesine neden olabilmektedir. Bu anlamda petrol fiyatları ve döviz kurları arasındaki bu önemli ilişki, gerek politika yapıcılar gerek de yatırımcılar tarafından yakından takip edilmektedir (Reboredo, 2012, s. 419-420).

Teorik olarak, petrol fiyatlarında yaşanacak artışlar, petrol ihraç eden ülkelerde döviz arzının artmasına ve beraberinde döviz kurlarının değerlenmesine katkı sağlamaktadır. Bu durum petrol ithal eden ülkeler için ters yönde işlemekte ve artan petrol fiyatları neticesinde daha fazla döviz talebi ile karşılaşılmasına ve beraberinde döviz kurlarında bir değer kaybının yaşanmasına neden olmaktadır. Petrol fiyatları ile döviz kuru arasındaki ilişkiyi inceleyen ilk çalışmalardan biri olan Golub (1983), çalışmasında petrol fiyatlarındaki artışların gelir, cari işlemler dengesi ve tasarruf gibi makroekonomik akımları etkilediğini ve bu durumun petrol ithal eden ve ihraç eden ülkeler arasındaki servet dağılımı üzerinde olumsuz etkiler meydana getirdiğini ileri sürmektedir. Buna göre petrol fiyatlarında yaşanacak artışlar belirli bir süre için petrol ihraç eden ülkelerin cari fazla ve petrol ithal eden ülkelerin ise cari açık vermelerine neden olabilir. Nihai olarak ise ortaya çıkacak servetin yeniden tahsisi, farklı portföy tercihleri nedeniyle döviz kurlarını etkileyebilmektedir (Golub,1983, s. 589).

Ham petrol fiyatlarındaki bir artış bir ülkenin para biriminin değerini artırıyorsa, bu durumda ham petrol fiyatındaki bir düşüşün de para birimine aynı oranda değer kaybettirmesi gerekmektedir. Bu durum ham petrolün bir ülkenin döviz kurunu simetrik olarak etkilediğini göstermektedir. Petrol fiyatındaki artış ve azalışların döviz kuru üzerindeki etkisinin işaret ve/veya büyüklük olarak değişmesi muhtemel olduğundan, petrol fiyatı değişiklikleri için simetri varsayımı gerçek dünyada her zaman doğru olmayabilir. Eğer petrol fiyatlarının döviz kurları üzerindeki etkileri asimetrik ise, simetriklik varsayımı altında yapılan ampirik çalışmaların sonuçları yanıltıcı olabilmektedir. Bu nedenle, petrol fiyatlarının döviz kurları üzerindeki etkileri incelenirken daha keskin değerlendirmeler yapabilmek 
için asimetrik varsayımın göz önünde bulundurulması büyük önem arz etmektedir (Baek ve Kim, 2020, s. 120).

Şekil 1'de yıllara göre ham petrol fiyatları (brent) ile Türkiye'ye ait reel döviz kuru ve cari işlemler dengesi (milyon \$) değerleri verilmiştir. Buna göre Türkiye ekonomisi iki farklı dönem itibari ile ele alınabilir. Bunlardan ilki cari işlemler dengesinin istikrarlı bir süreci takip ettiği 1975-2001 dönemlerini kapsamaktadır. Bu dönemde ayrıca (özellikle Türkiye ekonomisinin dışa açılmaya başladığı 1980'li yıllar itibari ile) gerek petrol fiyatları ve gerek de reel döviz kurlarında da istikrarlı bir sürecin yaşandığı dikkat çekmektedir. Diğer taraftan ikinci dönem ise Türkiye ekonomisinin ciddi bir ekonomik kriz ile karşılaştığı 2001 yılı ve sonrasını kapsamaktadır. Bu dönemde yurtiçinde yaşanan ekonomik problemlerin yanı sıra özellikle dünya petrol fiyatlarında yaşanan olumsuz gelişmeler, Türkiye'nin cari işlemler açı̆̆ı ile karşılaşmasına neden olmuştur. Üretim sürecinin vazgeçilmez unsurlarından hammadde ve petrol ürünlerinde yaşanan fiyat artışları, ithalat maliyetinin artmasına ve beraberinde cari açıkla karşılaşılmasına neden olmaktadır. Şekil 1'de petrol fiyatları ile cari işlemler dengesi arasındaki negatif ilişki açık bir şekilde gözlemlenmekte ve özellikle 2002 yılı itibariyle Türkiye'nin sürekli cari açık veren bir ülke haline geldiği anlaşılmaktadır. 


\section{Şekil 1. Yıllara Göre Reel Döviz Kuru, Ham Petrol Fiyatları (Brent) ve Cari İşlemler Dengesi (Milyon \$)}

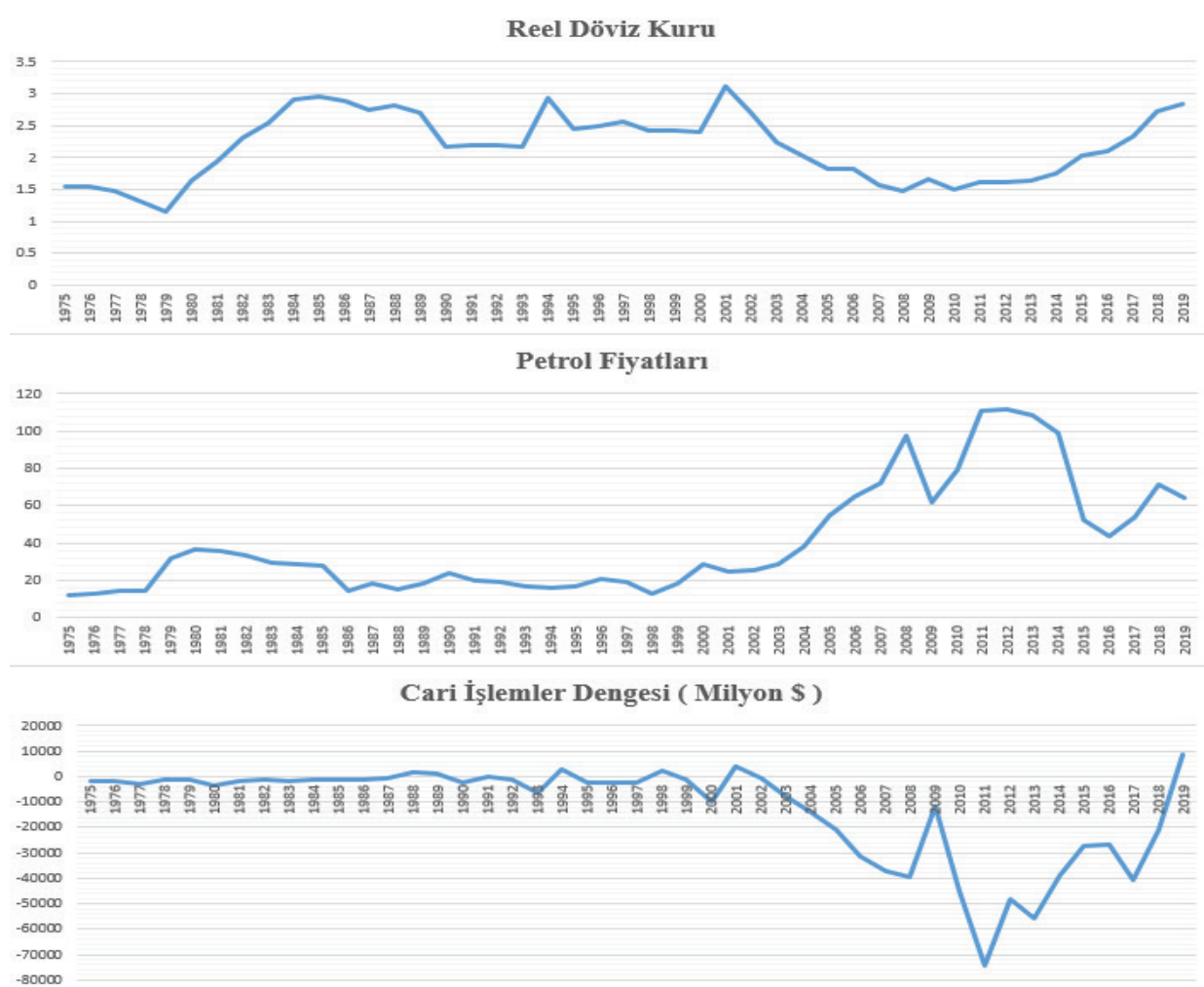

Kaynak: Hazine ve Maliye Bakanlığı Dünya Bankası, British Petroleum

Ülkelerin ekonomik performansları üzerinde önemli bir üretim girdisi olan petrol ve petrol ürünlerine yönelik talep, küresel ölçekte olduğu gibi Türkiye'de de gün geçtikçe artmaktadır. Türkiye ham petrol ihtiyacının büyük bir kısmını rezervlerinin sınırlı olması nedeniyle ithalat yoluyla karşılamaktadır. Bu nedenle petrol fiyatları ile döviz kurları arasındaki nedenselliğin yönünün belirlenmesi, ilişkinin dinamiklerini daha iyi anlamak açısından politika yapıcılara ve yatırımcılara önemli bilgiler sunmaktadır. Bu doğrultuda bu çalışmada Türkiye için 1960-2019 dönemi yıllık veriler kullanılarak petrol fiyatları ile reel döviz kuru değişkenleri arasındaki simetrik ve asimetrik nedensellik ilişkiler araştııılmıştır. Hem ham petrol fiyatları ile reel döviz kuru serileri arasındaki ilişki hem de bu serilerin pozitif ve negatif şoklar arasındaki nedensellik ilişkileri Fourier Toda-Yamamoto yöntemi kullanılarak incelenmiştir. 
Çalışmanın geri kalanı şu şekilde planlanmıştır. İkinci bölümde petrol fiyatları ile reel döviz kuru ilişkisini ele alan ampirik literatür incelenmiştir. Üçüncü bölümde çalışmada kullanılan ekonometrik yöntemler tanıtılmıştır. Dördüncü bölümde ampirik bulgular yer almaktadır. Beşinci bölümde sonuç ve politika önerilerine yer verilerek çalışma sonlandırılmıştır.

\section{Literatür}

Ham petrol fiyatları ve döviz kurları arasındaki ilişki hızla büyüyen bir ampirik literatürün konusu olmuştur. Bu çalışmalardan Amano ve Norden (1998), ABD petrol fiyatları ile döviz kuru arasındaki ilişkiyi 1972:02 - 1993:01 dönemine ait aylık veriler ile Johansen-Juselius eşbütünleşme testini kullanarak incelemiş ve eşbütünleşme ilişkisinin olduğu sonucuna ulaşmıştır.

Sadorsky (2000), 1987:01-1997:09 aylık verilerini kullanarak petrol fiyatları ile ticaret ağırlıklı ABD döviz kuru arasındaki ilişkiyi araştırmıştır. Nedensellik analizi sonuçları ham petrol fiyatlarından döviz kuruna doğru nedensellik ilişkisinin olduğunu göstermektedir.

Camarero ve Tamarit (2002), 1973-1997 yıllık verileri ile panel eşbütünleşme analizini kullanarak, reel döviz kuru, reel faiz oranı ve reel petrol fiyatları arasındaki ilişkiyi incelemişlerdir. Çalışmada reel petrol fiyatının uzun dönemde reel döviz kurunun ana belirleyicilerinden biri olduğunu sonucuna ulaşılmıştır.

Chen ve Chen (2007), G7 ülkeleri için 1972:01- 2005:10 dönemi aylık panel verileri ile reel petrol fiyatları ile reel döviz kurları arasındaki uzun dönemli ilişkiyi araştırmıştır. Reel döviz kuru hareketlerinin baskın kaynağının reel petrol fiyatları olabileceği ve reel petrol fiyatları ile reel döviz kurları arasında bir ilişki olduğu sonucuna ulaşmışlardır.

Huang ve Guo (2007), petrol fiyatı şokunun ve altta yatan diğer üç tür makroekonomik şokun Çin'in reel döviz kurunun trend hareketlerini ne ölçüde etkilediğini araştırmaktadır. Çalışmalarında dört boyutlu bir yapısal Vektör 
Otoregresif (VAR) modelinin kullanmışlardır. Elde edilen sonuçlar, reel petrol fiyat şoklarının uzun vadeli reel döviz kurunun küçük bir değer kazanmasına yol açacağını göstermektedir.

Zhang, Fan, Tsai ve Wei (2008), 2000:01- 2005:05 aylık verilerini kullanarak USD döviz kurunun uzun vadede petrol fiyatları üzerinde önemli bir etkiye sahip olduğunu ve kısa vadede ise etkisinin sınırlı olduğuna dair bulgular elde etmiştir.

Lizardo ve Mollick (2010) çalışmalarında 1970-2008 dönemine ait yıllık verileri kullanarak petrol fiyatı şoklarının USD'nin değerini nasıl etkilediğini Johansen eşbütünleşme testi ile incelemişlerdir. Analiz sonucunda petrolün reel fiyatındaki artışın, Kanada, Meksika ve Rusya gibi net petrol ihracatçısı ülkelerde ABD dolarının önemli ölçüde değer kaybetmesine yol açtığını belirtmişlerdir. Ayrıca Japonya gibi petrol ithalatçısı ülkelerin para birimlerinde ise USD karşısında değer kaybına neden olduğu sonucuna ulaşmışlardır.

Cifarelli ve Paladino (2010), çok değişkenli bir genelleştirilmiş otoregresif koşullu değişen varyans-ortalama (GARCH-M) modelini kullanarak, petrol fiyatlarındaki değişimlerin döviz kuru değişimleri ile negatif ilişkili olduğuna dair güçlü kanıtlar elde etmişlerdir.

Basher, Haug ve Sadorsky (2012) çalışmasında 1988:01 - 2008:12 dönemi aylık verilerini kullanarak petrol fiyatları, döviz kurları ve gelişen piyasa hisse senetleri arasındaki dinamik ilişkiyi araştırmışlardır. Yapısal VAR modelinin kullanıldığı çalışmada petrol fiyatlarına yönelik pozitif şokların, kısa vadede gelişen piyasa hisse senedi fiyatlarını ve döviz kurlarını aşağı çekme eğiliminde olduğu sonucuna ulaşmışır.

Adıgüzel, Bayat, Kayhan ve Nazlıŏlu (2013) Brezilya, Hindistan ve Türkiye'yi ele aldığı çalışmasında, her bir ülke için esnek döviz kuru rejiminin başlamasından 2011:07 dönemine ait aylık verileri kullanmışlardır. Ham petrol fiyatları ile döviz kurları arasındaki nedensellik ilişkinin ele alındığı çalışmada zaman dağııımı nedensellik testleri ve frekans dağılımı nedensellik testleri kullanılmıştır. Çalışma 
sonucunda frekans dağııımı nedensellik testi ile zaman dağılımı nedensellik testleri sonuçlarının farklılık gösterdiği belirtilmiştir. Ayrıca frekans dağılımı nedensellik sonuçlarına göre, Hindistan için iki yönlü nedensellik elde edilirken, Brezilya ve Türkiye için reel döviz kurundan petrol fiyatlarına doğru tek yönlü nedensellik ilişkisinin olduğu bulgusuna ulaşmışlardır.

Adıgüzel, Kayhan ve Bayat (2016) çalışmalarında, 2009:01-2015:12 dönemi aylık verilerini kullanılarak Türkiye'de petrol fiyatları ile döviz kuru arasındaki ilişkiyi Hatemi-J ve Roca (2014) tarafından önerilen asimetrik nedensellik analizi kullanarak incelemişlerdir. Petrol fiyatlarından döviz kuruna nedensellik ilişkisinin olduğunu ve ilişkinin asimetrik bir davranış sergilediği sonucuna ulaşmışlardır.

Ağazade (2018) çalışmasında, 1995:01- 2017:09 aylık verilerini kullanarak Azerbaycan için reel döviz kuru ve dünya reel petrol fiyatları ilişkisini incelemiştir. Asimetrik uyarlamayı da dikkate alan TAR ve MTAR eşbütünleşme yöntemlerinin kullanıldığı çalışmada reel döviz kurunun reel petrol fiyatlarına asimetrik şekilde uyarlanmasını destekleyen zayıf bulgulara ulaşılmıştır.

Şit ve Alancıoğlu (2019) 2008:01-2018:06 dönemi aylık verileri ile Türkiye'de petrol fiyatları ve döviz kuru arasındaki ilişkiyi Philipps-Oualiris ve Engle-Granger eşbütünleşme ve Granger nedensellik testlerini kullanarak araştırmışlardır. Elde edilen sonuçlara göre petrol fiyatları ile döviz kuru arasında eşbütünleşme ilişkisi olduğunu ve petrol fiyatlarından döviz kuruna doğru nedensellik ilişkisinin var olduğu sonucuna ulaşmışlardır.

Baek ve Kim (2020) çalışmalarında, 2000:01- 2017:06 dönemi için aylık veriler ile 11 seçilmiş Sahra Altı Afrika ülkesi için doğrusal olmayan ARDL modelini kullanarak, döviz kuru ve petrol fiyatı değişikliklerinin asimetrik etkilerini incelemişlerdir. Analiz sonucunda, petrol fiyatlarındaki değişikliklerin uzun dönemde reel döviz kurları üzerinde asimetrik etkilere sahip olduğu bulgusu elde edilmiştir. Ayrıca kısa vadede ise petrol fiyatlarındaki değişimlerin asimetrisi gözlenmemiştir.

Saidu, Naseem, Law ve Yasmin (2021), 1983:Q2-2018:Q4 dönemi çeyreklik verileri ile Afrika'nın başlıca net petrol ithalatçısı ülkelerinde döviz kuru ve petrol 
fiyatlarındaki değişikliklerin etkilerini araştırmışlardır. Çalışmada doğrusal ARDL tekniği ve doğrusal olmayan ARDL tekniği kullanılmıştır. Analiz sonucunda, petrol fiyatı değişikliklerinin döviz kurunun davranışını etkilediği ve ulusal ekonomik ilerlemenin gelişiminde önemli olduğuna dair bulgulara ulaşmışlardır.

Yapılan çalışmalar incelendiğinde petrol fiyatları ve döviz kuru arasındaki ilişki ülkenin net petrol ithalatçısı veya ihracatçısı olması durumuna göre değiştiği açıktır. Türkiye için yapılan çalışmalar incelendiğinde ise petrol fiyatları ve döviz kuru arasındaki ilişkiyi nedensellik bağlamında ele alan az sayıda çalışma olduğu görülmüştür. Adıgüzel ark. (2016), Şit ve Alancıoğlu (2019), petrol fiyatlarından döviz kuruna nedensellik ilişkisinin var olduğu, Adıgüzel ark. (2013), reel döviz kurundan petrol fiyatlarına tek yönlü nedensellik olduğu bulgusuna ulaşmışlardır. Literatürde uygulanan ekonometrik yöntemler incelendiğinde simetriklik ve asimetriklik kavramının bu ilişkiyi doğru bir şekilde belirlemek için kritik bir nokta olduğu görülmektedir. Bu çalışmada asimetrik etkiler göz önüne alınarak Fourier nedensellik analizi yapılmıştır. Çalışma ele alınan dönem ve kullanılan ekonometrik yöntem bakımından diğer çalışmalardan ayrılmaktadır.

\section{Veri Seti ve Ekonometrik Yöntem}

Bu çalışmada 1960-2019 dönemi yıllık veriler kullanılmış ve Türkiye için petrol fiyatları ile reel döviz kuru değişkenleri arasındaki asimetrik nedensellik ilişkileri araştırılmıştır. Bu doğrultuda hem petrol fiyatları ile reel döviz kuru serileri arasındaki hem de bu serilerin pozitif ve negatif şokları arasındaki nedensellik ilişkileri Fourier Toda-Yamamoto yöntemi kullanılarak incelenmiştir. Değişkenlerin durağanlık özelliklerini ortaya koymak için Genişletilmiş Dickey-Fuller (ADF), Phillips-Perron (PP) ve Christopoulos ve Leon-Ledesma (2010) tarafından geliştirilen Fourier ADF birim kök testleri kullanılmıştır. Ham petrol fiyatları (Brent) verilerine BP Statistical Review of World Energy (Haziran 2020) veri tabanından, reel döviz kuru verilerine ise Dünya Bankası web sayfasından ulaşılmıştır. Analizlerde kullanılmadan önce serilerin logaritmaları alınmıştır. 
Şekil 2. Çalışmada Kullanılan Seriler ve Fourier Yaklaşımları
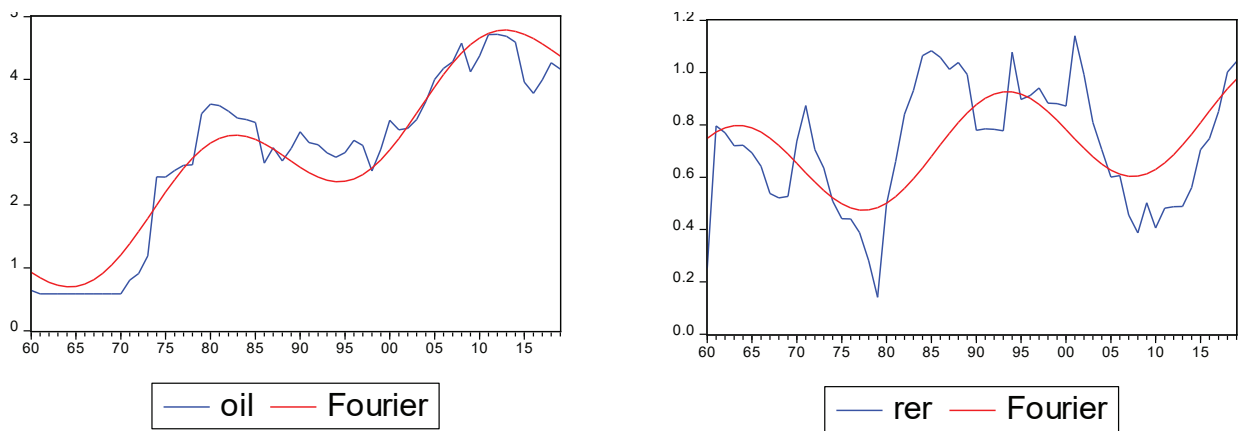

Şekil 2'de çalışmada kullanılan serileri ve Fourier yaklaşımı ile yapısal değişimleri göstermektedir. Yumuşak ve pürüzsüz kırılmaları ele alan Fourier yaklaşımının genel itibariyle serilere uyumunun iyi olduğu görülmektedir. Bu nedenle birim kök ve nedensellik analizlerinde yapısal kırılmaları göz önüne alabilmek için Fourier yaklaşımının kullanılması daha uygun olacaktır.

\subsection{Fourier ADF Birim Kök Testi}

Perron (1989) yapmış olduğu çalışmada, veri üretme sürecinde yapısal kırılmaların dikkate alınmadığı durumlarda kırımaları dikkate almayan birim kök testlerinin güç kaybettiğini belirtmiştir. Christopoulos ve Leon-Ledesma (2010), Fourier yaklaşımını kullanarak yapısal kırılmaları dikkate alan Fourier ADF birim kök testini geliştirmişlerdir. Christopoulos ve Leon-Ledesma (2010) prosedürü, birinci aşamada Fourier formunu kullanmaya ve ikinci aşamada ise ADF testini uygulamaya dayanmaktadır.

Bir stokastik $y_{t}$ değişkeni için aşağıda verilen model dikkate alınabilir:

$$
y_{t}=d(t)+v_{t}
$$

Burada $v_{t} \sim N(0, \sigma)$ ve $d(t)$ zamanla değişen deterministik bir bileşendir. Christopoulos ve Leon-Ledesma (2010), $d(t)$ terimi için aşağıda verilen Fourier serilerini kullanmışlardır:

$$
d(t)=\gamma_{0}+\gamma_{1} \sin \left(\frac{2 \pi k t}{T}\right)+\gamma_{2} \cos \left(\frac{2 \pi k t}{T}\right)
$$


Bu kapsamda Denklem (1) ile verilen modelde yer alan $d(t)$ terimi yerine Denklem (2)'de verilen ifade yazılırsa aşağıda verilen model elde edilmektedir:

$$
y_{t}=\gamma_{0}+\gamma_{1} \sin \left(\frac{2 \pi k t}{T}\right)+\gamma_{2} \cos \left(\frac{2 \pi k t}{T}\right)+v_{t}
$$

Boş hipotez $H_{0}: v_{t}=\mu_{t}, \mu_{t}=\mu_{t-1}+h_{t}$ olarak ifade edilebilir. Burada $h_{t}$ 'nin sıfır ortalama ile durağan bir süreç olduğu varsayılmaktadır. Christopoulos ve LeonLedesma (2010) tarafından önerilen Fourier ADF testi için test istatistiği üç adımlı bir prosedür ile elde edilmektedir.

Adım 1: Illk adım, uygun frekans değerinin $\left(k^{*}\right)$ elde edilmesini içermektedir. 1 ile 5 arasındaki değerleri için En Küçük Kareler (EKK) yöntemi kullanılarak Denklem (3) tahmin edilmekte ve kalıntı kareler toplamını minimum yapan $k$ değeri seçilmektedir. Daha sonra modelin EKK kalıntıları hesaplanmaktadır.

Adım 2: İkinci adımda, elde edilen EKK kalıntılarına birim kök testi uygulanmaktadır:

$$
\hat{v}_{t}=y_{t}-\hat{\gamma}_{0}+\hat{\gamma}_{1} \sin \left(\frac{2 \pi k^{*} t}{T}\right)+\hat{\gamma}_{2} \cos \left(\frac{2 \pi k^{*} t}{T}\right)
$$

Denklem (5) ile verilen Fourier ADF modelinde standart ADF regresyonu kullanılmaktadır. Fourier ADF modeli için birim kökün varlı̆̆ını ifade eden boş hipotezi, alternatif hipotezine karşı test edilmektedir.

$$
\Delta v_{t}=\alpha_{1} v_{t-1}+\sum_{j=1}^{p} \beta_{j} \Delta v_{t-j}+u_{t}
$$

Adım 3: Bu adımda trigonometrik terimlerin anlamllığı incelenmektedir. Model (3) için boş hipotezini alternatif hipoteze karşı sınanmak amacıyla $\mathrm{F}$ testi kullanılmaktadır. Eğer Fourier ADF modelinde boş hipotez reddedilirse ele alınan değişkenin kırılmalı deterministik bir fonksiyon etrafında durağan olduğu sonucuna varılabilmektedir.

\subsection{Asimetrik Fourier Nedensellik Testi}

Granger nedensellik testi VAR modeli temel aldığından, durağan olmayan değişkenler söz konusu olduğunda bu değişkenleri durağan hale getirmek için farklarının alınması gerekmektedir. Ancak değişkenlerin farklarının alınması uzun 
dönemde bilgi kaybına neden olmaktadır. Toda ve Yamamoto (1995) tarafından önerilen nedensellik testi artııılmıs VAR modelini temel aldığından değişkenlerin bütünleşme özelliklerinden bağımsız olarak uygulanabilmektedir. Nazlioglu, Gormus ve Soytaş (2016) tarafından önerilen Fourier nedensellik testi, Toda ve Yamamoto (1995) tarafından geliştirilen nedensellik yaklaşımını temel almaktadır. Toda ve Yamamoto (1995) nedensellik testi yapısal kırılmaların varlığını dikkate almamaktadır. Eğer ele alınan serilerde yapısal kırılma varsa, bu durumda yapılan analizlerde sapmalı sonuçlar elde edilebilmektedir. Fourier Toda-Yamamoto analizinde nedensellik ilişkisinin olmadığını ifade eden boş hipotez Denklem (6) ile tanımlanan model ile sınanmaktadır:

$$
y_{t}=\alpha_{0}+\gamma_{1} \sin \left(\frac{2 \pi k t}{T}\right)+\gamma_{2} \cos \left(\frac{2 \pi k t}{T}\right)+\beta_{1} y_{t-1}+\cdots+\beta_{p+d} y_{t-(p+d)}+e_{t}
$$

Burada $k$ Fourier yapısı için uygun frekans sayısını, $t$ deterministik trendi, $T$ gözlem sayısını, p VAR modeli ile elde edilen uygun gecikme uzunluğunu, maksimum bütünleşme derecesini ifade etmektedir. $e_{t}$ ise beyaz gürültülü (white noise) süreç özelliklerini taşıyan kalıntıları göstermektedir. Denklem (6)'da uygun $p$ ve $k$ değerleri Akaike veya Schwarz bilgi kriterleri kullanılarak seçilmektedir. Fourier Toda-Yamamoto testinde boş hipotez $H_{0}: \beta_{1}=\cdots=\beta_{p}$ olarak ifade edilmektedir.

Kişilerin, firmaların ve karar birimlerinin pozitif ve negatif şoklara tepkileri farklıdır. Asimetrik ilişkileri dikkate almayan nedensellik analizlerinde, pozitif bir şokun etkisinin mutlak anlamda negatif bir şokun etkisi ile aynı olduğu varsayılmaktadır. Pozitif ve negatif şokun etkilerinin bir bütün olarak analiz edilmesi, saklı nedensellik ilişkilerinin göz ardı edilmesine yol açmaktadır. Bu durum kısıtlayıcı bir varsayım olabilmektedir çünkü birçok durumda nedensellik etkilere ilişkin potansiyel olarak asimetrik bir yapı bulunmaktadır. Hatemi-J (2012), saklı nedensellik ilişkileri ortaya çıkarmak için değişkenleri pozitif ve negatif şoklar olarak ayırmayı ve bu şoklara nedensellik testi uygulanmasını önermiştir (Pata, 2020, s. 1152). Hatemi-J (2012) pozitif ve negatif şokların kümülatif toplamlarını oluşturarak nedensellik testinde asimetrik davranışı dikkate almayı önermektedir. Bu çalışmada Yılancı, Özgür ve Görüş (2019)'ün çalışması takip edilerek asimetrik Fourier nedensellik testi yapılmıştır. Asimetrik Fourier nedensellik testinde 
Denklem (6)'da yer alan $y_{t}$ terimine şoklar eklenmektedir. Bu test prosedüründe ele alınan değişkenler Denklem (7) ve Denklem (8)'de verildiği gibi pozitif ve negatif bileşenlere dönüştürülmektedir.

$$
\begin{gathered}
o i l_{t}=\operatorname{oil}_{t-1}+\varepsilon_{1 t}=o i l_{0}+\sum_{i=1}^{t} \varepsilon_{1 i}^{+}+\sum_{i=1}^{t} \varepsilon_{1 i}^{-} \\
\operatorname{rer}_{t}=\operatorname{rer}_{t-1}+\varepsilon_{2 t}=\operatorname{rer}_{0}+\sum_{i=1}^{t} \varepsilon_{2 i}^{+}+\sum_{i=1}^{t} \varepsilon_{2 i}^{-}
\end{gathered}
$$

Burada oil ${ }_{0}$ ve rer $_{0}$ değişkenlerin başlangıç değerlerini, $\varepsilon_{i}^{+}$ve $\varepsilon_{i}^{-}$ise sırasıyla pozitif ve negatif şokları göstermektedir. Daha sonra şoklar Fourier nedensellik denklemine dâhil edilmektedir. Bu çalışmada, reel döviz kurunun pozitif ve negatif şokları ile petrol fiyatlarının pozitif ve negatif şokları arasında nedensellik ilişkisinin olup olmadığı araştırılmaktadır.

\section{Ampirik Bulgular}

Bu bölümde petrol fiyatları ile reel döviz kuru değişkenleri arasındaki nedensellik ilişkileri araştırılacaktır. Nedensellik testini uygulamadan önce çalışmada kullanılan değişkenlerin bütünleşme derecelerinin belirlenmesi gerekmektedir. Değişkenlerin bütünleşme derecelerini tespit etmek amacıyla öncelikle ADF ve PP birim kök testleri uygulanmış ve elde edilen sonuçlar Tablo 1 'de sunulmuştur.

Tablo 1'den görülebileceği üzere ADF ve PP testi sonuçları çalışmada kullanılan değişkenlerin düzey değerlerinde birim köklü olduğunu (PP testinde rer değişkeni hariç), serilerin birinci farkları alındığında ise durağan hale geldiklerini göstermektedir. Ekonometrik analizin ikinci aşamasında Fourier ADF birim kök testi kullanılmıştır. Fourier ADF birim kök analizi sonuçları Tablo 2 ile verilmiştir. 
Tablo 2: FADF Birim Kök Analizi

\begin{tabular}{|c|c|c|c|c|c|c|}
\hline \multirow{2}{*}{ Değişken } & \multicolumn{3}{|c|}{ Düzey } & \multicolumn{3}{c|}{ 1. Fark } \\
\cline { 2 - 7 } & Frekans (k) & Fourier ADF & F-istatistiği & Frekans (k) & Fourier ADF & F-isstatistiği \\
\hline oil & 2 & -1.542 & $24.68^{*}$ & 2 & $-5.782^{*}$ & $4.57^{\star * *}$ \\
\hline rer & 2 & $-3.741^{\star *}$ & $10.02^{*}$ & 2 & $-8.294^{*}$ & 2.47 \\
\hline oil $^{+}$ & 1 & -1.400 & $37.25^{\star}$ & 2 & $-5.580^{*}$ & 3.85 \\
\hline rer $^{+}$ & 1 & 0.001 & $46.12^{\star}$ & 5 & $-9.540^{*}$ & 2.59 \\
\hline oil- $^{-}$ & 1 & 0.098 & $66.68^{*}$ & 2 & $-8.007^{*}$ & 2.72 \\
\hline rer $^{-}$ & 1 & -1.664 & $42.20^{*}$ & 2 & $-4.499^{*}$ & $4.35^{* * *}$ \\
\hline
\end{tabular}

Not: *, ** ve *** sırasıyla \%1, \%5 ve \%10 düzeyinde anlamlılı̆ı ifade etmektedir.

Tablo 2'de verilen $\mathrm{F}$ testi sonuçları incelendiğinde serilerin düzey değerlerinden elde edilen F-istatistiği değerleri kritik değerlerden büyük olduğu için doğrusal olmayan trendin anlamsız olduğunu ifade eden boş hipotez reddedilerek, Fourier terimlerin anlamlı olduğu sonucuna ulaşılmıştır. Birinci farkları alındığında ise oil ve rer ' serileri için Fourier terimlerinin anlamlı diğer seriler için anlamsız olduğu görülmektedir. Fourier ADF birim kök testi sonuçları incelendiğinde rer değişkeni hariç ele alınan serilerin düzey değerlerinde durağan olmadıkları sonucuna ulaşılmıştır. Bu serilerin birinci farkları kullanıldığında ise durağan oldukları görülmektedir. Ekonometrik analizin üçüncü ve son aşamasında değişkenler arasındaki nedensellik ilişkileri asimetrik Fourier nedensellik analizi ile incelenmiş ve elde edilen sonuçlar Tablo 3 ile verilmiştir.

Tablo 3: Asimetrik Fourier Nedensellik Analizi

\begin{tabular}{|c|c|c|c|c|c|}
\hline Değişken & Wald İstatistiği & Frekans & Var (p) & $\mathbf{d}_{\max }$ & $\begin{array}{c}\text { Bootstrap } \\
\text { p-değeri }\end{array}$ \\
\hline oil $\rightarrow$ rer & 3.020 & 2 & 2 & 1 & 0.232 \\
\hline rer $\rightarrow$ oil & 1.306 & 2 & 2 & 1 & 0.518 \\
\hline oil $^{+} \rightarrow$ rer $^{+}$ & $6.038 * * *$ & 2 & 2 & 1 & 0.070 \\
\hline rer $^{+} \rightarrow$ oil $^{+}$ & 0.251 & 2 & 2 & 1 & 0.882 \\
\hline oil $^{-} \rightarrow$ rer $^{-}$ & 1.083 & 2 & 1 & 1 & 0.298 \\
\hline rer $^{-} \rightarrow$ oil $^{-}$ & 0.027 & 2 & 1 & 1 & 0.868 \\
\hline
\end{tabular}

Not: ${ }^{*}{ }^{* *}$ ve ${ }^{* * *}$ sırasıyla; \%1, \%5 ve \%10 düzeyinde anlamlılığı ifade etmektedir. Bootstrap kritik değerler 10.000 döngü ile elde edilmiştir. Uygun gecikme uzunluğu gösteren Var (p) değerleri, HJC Bilgi kriteri kullanılarak tespit edilmiştir. 
Tablo 3'den görülebileceği gibi simetrik nedensellik testi sonuçlarına göre nedensellik ilişkisinin olmadığını ifade eden boş hipotez reddedilememektedir. Yani petrol fiyatları ile reel döviz kuru değişkenleri arasında nedensellik ilişkisinin olmadığı görülmektedir. Asimetrik Fourier nedensellik testi sonuçları ise pozitif petrol fiyatı şoklarından pozitif reel döviz kuru şoklarına doğru tek yönlü nedensellik ilişkisinin olduğunu göstermektedir. Ayrıca negatif şoklar arasında ise nedensellik ilişkisi elde edilememiştir. Nedensellik ilişkisinin simetrik nedensellik testi ile elde edilemeyip asimetrik Fourier nedensellik testi ile elde edilmesi nedensellik ilişkileri araştırılırken saklı nedensellik ilişkilerinin göz önünde bulundurulmasının önemini ortaya koymaktadır.

\section{Sonuç}

Bu çalışmada Türkiye için petrol fiyatları ile reel döviz kuru değişkenleri arasındaki asimetrik nedensellik ilişkileri araştııılmışır. Bu doğrultuda ham petrol fiyatları ile reel döviz kuru serileri arasındaki nedensellik ilişkileri asimetrik Fourier Toda-Yamamoto yöntemi kullanılarak incelenmiştir. Kullanılan nedensellik analizinin üç önemli avantajı bulunmaktadır. Birincisi, ele alınan serilerin farklı bütünleşme dereceleri ile analize dâhil edilmesine izin verilmektedir. Yani durağan olmayan değişkenler söz konusu olduğunda bu değişkenlerin farklarının alınmasına gerek kalmadan uygulanabilmektedir. İkincisi, kullanılan Fourier yapı sayesinde yapısal kırılmalar dikkate alınmaktadır. Serilerde yapısal kırılmaların varlığı durumunda yapısal kırılmaları dikkate almayan testler ile yapılan analizler sapmalı sonuçlar verebilmektedir. Üçüncüsü, değişkenlere ait pozitif ve negatif şoklar kullanılarak nedensellik testinde asimetrik davranış dikkate alınmaktadır.

Elde edilen sonuçlar petrol fiyatları ile reel döviz kuru değişkenleri arasında simetrik nedensellik ilişkisinin olmadığını, fakat pozitif petrol fiyatı şoklarından pozitif reel döviz kuru şoklarına doğru tek yönlü nedensellik ilişkisinin olduğunu göstermektedir. Yani petrol fiyatlarının artması Türkiye'de reel döviz kurunun artmasına neden olmaktadır. Bu sonuçlara göre, Türkiye'de petrol fiyatları ile döviz kuru ilişkisi incelenirken asimetrik etkilerin göz önünde bulundurulması gerekmektedir. Türkiye'deki ekonomik faaliyetlerin sürdürülebilirliği ile ilgili olarak 
petrol ithalatı oldukça önemli bir yere sahiptir. Bu anlamda petrol fiyatlarında yaşanacak artışlar Türkiye'nin ithalat maliyetlerini ve dolayısıyla döviz talebini arttırmaktadır. Döviz talebindeki artışlar ise alternatif gelir kaynağının sınırlı olması nedeniyle Türkiye'deki döviz kurlarının yönünde baskı yaratmaktadır. Döviz kurunda yaşanan artışlar ise başta cari açık ve maliyet enflasyonu olmak üzere ülkenin makroekonomik dengelerini oldukça olumsuz etkileyen koşulların oluşmasına neden olmaktadır. Bu anlamda Türkiye'nin ithalat kalemleri içerisinde önemli bir yere sahip olan petrol ürünlerine yönelik bağımlılığı uzun vadede azaltabilecek politikalar geliştirilmelidir. Özellikle alternatif temiz enerji kaynaklarını (güneş, rüzgâr, nükleer ve hidroelektrik gibi) geliştirerek enerji tüketiminin çeşitlendirilmesini teşvik eden yapısal reformları uygulanması önerilmektedir.

\footnotetext{
Hakem Değerlendirmesi: Dış bağımsız.

Çıkar Çatışması: Yazar çıkar çatışması bildirmemiştir.

Finansal Destek: Yazar bu çalışma için finansal destek almadığını beyan etmiştir.

Peer-review: Externally peer-reviewed.

Conflict of Interest: The author has no conflict of interest to declare.

Grant Support: The author declared that this study has received no financial support.
}

\section{Kaynaklar/References}

Adıgüzel, U., Bayat, T., Kayhan, S., \& Nazlığlu, Ş. (2013). Oil prices and exchange rates in Brazil, India and Turkey: Time and frequency domain causality analysis. Siyaset, Ekonomi ve Yönetim Araştırmaları Dergisi, 1(1), 49-73.

Adıgüzel, U., Kayhan, S. ve Bayat, T. (2016). Petrol fiyatları ve döviz kuru arasındaki ilişkinin ampirik analizi: Asimetrik nedensellik analizi. Cumhuriyet Üniversitesi Iktisadi ve İdari Bilimler Dergisi, $17(2), 241-252$.

Ağazade, S. (2018). Reel döviz kuru ve petrol fiyatları ilişkisinde asimetri: Azerbaycan örneğinde bir inceleme. Uluslararası İktisadi ve Idari Incelemeler Dergisi, 2018 (Prof. Dr. Harun Terzi Özel Sayısı), 113-126.

Amano, R. A. \& Van Norden, S. (1998). Oil prices and the rise and fall of the US real exchange rate. Journal of International Money and Finance, 17, 299-316.

Baek, J. \& Kim, H. Y. (2020). On the relation between crude oil prices and exchange rates in SubSaharan African countries: A nonlinear ARDL approach. The Journal of International Trade \& Economic Development, 29(1), 119-130.

Basher, S. A., Haug, A. A. \& Sadorsky, P. (2012). Oil prices, exchange rates and emerging stock markets. Energy Economics, 34(1), 227-240. 
Bp (2021). Statistical Review of World Energy 2021 | 70th edition. Retrieved from https://www.bp. $\mathrm{com} /$ content/dam/bp/business-sites/en/global/corporate/pdfs/energy-economics/statisticalreview/bp-stats-review-2021-full-report.pdf

Camarero, M. \& Tamarit C. (2002). Oil prices and Spanish competitiveness: A cointegrated panel analysis. Journal of Policy Modeling, 24(6), 591-605.

Chen, S. S. \& Chen H. C. (2007). Oil prices and real exchange rates. Energy Economics, 29(3), 390-404.

Christopoulos, D. K., \& León-Ledesma, M. A. (2010). Smooth breaks and non-linear mean reversion: Post-Bretton Woods real exchange rates. Journal of International Money and Finance, 29(6), 1076-1093.

Cifarelli, G., \& Paladino, G. (2010). Oil price dynamics and speculation: A multivariate financial approach. Energy economics, 32(2), 363-372.

Golub, S. S. (1983). Oil prices and exchange rates. The Economic Journal, 93(371), 576-593.

Güneş, S., \& Yıldırım, C. (2013). The relationship between crude oil prices, real effective exchange rate and terms of trade: A causality analysis for Turkey. BiLTÜRK Ekonomi ve Ilişkili Çalışmalar Dergisi, 1(2), 112-130.

Hatemi-J, A. (2012). Asymmetric causality tests with an application. Empirical Economics, 43(1), 447456.

Hatemi-J, A., \& Roca, E. (2014). BRICs and PIGS in the presence of Uncle Sam and big brothers: Who drive who? Evidence based on asymmetric causality tests. Griffith Business School Discussion Papers Finance, ISSSN:1836-8123.

Huang, Y., \& Guo, F. (2007). The role of oil price shocks on China's real exchange rate. China Economic Review, 18(4), 403-416.

Lizardo, R. A., \& Mollick, A. V. (2010). Oil price fluctuations and US dollar exchange rates. Energy Economics, 32(2), 399-408.

Nazlioglu, S., Gormus, N. A., \& Soytas, U. (2016). Oil prices and real estate investment trusts (REITs): Gradual-shift causality and volatility transmission analysis. Energy Economics, 60, 168-175.

OPEC Annual Statistical Bulletin (2013). OPEC share of world crude oil reserves. 〈http://www.opec. org/opec_web/en/data_graphs/330.htm).

Pata, U. K. (2020). How is COVID-19 affecting environmental pollution in US cities? Evidence from asymmetric Fourier causality test. Air Quality, Atmosphere \& Health, 13(10), 1149-1155.

Perron, P. (1989). The great crash, the oil price shock, and the unit root hypothesis. Econometrica: Journal of the Econometric Society, 57(6), 1361-1401.

Reboredo, J. C. (2012). Modelling oil price and exchange rate co-movements. Journal of Policy Modeling, 34(3), 419-440.

Sadorsky, P. (2000). The empirical relationship between energy futures prices and exchange rates. Energy Economics, 22, 253-266.

Saidu, M. T., Naseem, N. A. M., Law, S. H., \& Yasmin, B. (2021). Exploring the asymmetric effect of oil price on exchange rate: Evidence from the top six African net oil importers. Energy Reports. 
Şit, M. ve Alancıoğlu, E. (2019). Türkiye ekonomisinde dünya petrol fiyatları ve döviz kuru ilişkisi: Ampirik analiz. Econharran, 3(3), 22-35.

Toda, H. Y., \& Yamamoto, T. (1995). Statistical inference in vector autoregressions with possibly integrated processes. Journal of Econometrics, 66(1-2), 225-250.

World Bank (2021). World Bank Open Data. Retrieved from https://data.worldbank.org/

Yılancı, V., Özgür, O., \& Görüş, M. S. (2019). The asymmetric effects of foreign direct investment on clean energy consumption in BRICS countries: A recently introduced hidden cointegration test. Journal of Cleaner Production, 237, 117786.

Zhang, Y. J., Fan, Y., Tsai, H. T., \& Wei, Y. M. (2008). Spillover effect of US dollar exchange rate on oil prices. Journal of Policy modeling, 30(6), 973-991. 